American Journal of Pharmaceutical Education 2018; 82 (6) Article 6298.

\title{
RESEARCH
}

\section{Designing and Evaluating an Interprofessional Practice Experience Involving Dental and Pharmacy Students}

\author{
Jacqueline Theodorou, PharmD, ${ }^{a}$ Melissa Rotz, PharmD, ${ }^{a}$ Laurie Macphail, DMD, PhD, ${ }^{b}$ \\ Chizobam Idahosa, DDS, MS, BDS, ${ }^{b}$ Maria L. Fornatora, DMD, ${ }^{\mathrm{b}}$ Elizabeth Tweddale, DMD, ${ }^{\mathrm{b}}$ \\ Shannon Myers Virtue, PsyD ${ }^{\mathrm{b}}$ \\ a Temple University School of Pharmacy, Philadelphia, Pennsylvania \\ b Temple University Kornberg School of Dentistry, Philadelphia, Pennsylvania \\ Submitted January 25, 2017; accepted May 9, 2017; published August 2018.
}

Objective. To prepare pharmacy and dental students to collaborate as members of an interprofessional team by participating in an interprofessional practice experience.

Methods. An interprofessional practice experience was implemented within a dental admissions clinic. Pharmacy and dental students collaboratively conducted medical histories and provided tobacco cessation education. Pharmacy student performance was measured using a standardized assessment rubric; pharmacy and dental student perceptions were measured using the SPICE-R tool; and faculty feedback was captured for evaluation purposes.

Results. Pharmacy students achieved performance expectations upon completion. There was a statistically significant increase in the mean scores for a majority of the SPICE-R factors for pharmacy and dental students. Overall, faculty perceptions of the practice experience were positive.

Conclusion. A collaboration between pharmacy and dental schools is a novel approach to meeting interprofessional and experiential curricular goals. Evaluating performance in practice experiences and perceptions can be used to demonstrate learner outcomes within interprofessional education. Furthermore, faculty feedback should be used to improve practice experiences.

Keywords: interprofessional education, dental, pharmacy, practice experience, perceptions

\section{INTRODUCTION}

Accreditation standards for pharmacy and dental schools highlight the importance of incorporating interprofessional education (IPE) into their respective curricula. The Accreditation Council for Pharmacy Education (ACPE) 2016 Standard 11 states that the key elements of IPE are interprofessional team dynamics, education, and team practice. The 2016 Standards state that for interprofessional team practice, all students have to participate "in experiential educational activities with prescribers/ student prescribers. . .including face-to-face interactions that are designed to advance interprofessional team effectiveness." $" 1,2$ Additionally, the Center for the Advancement of Pharmacy Education (CAPE) 2013 Educational Outcomes include a subdomain of interprofessional collaboration as an essential skillset for practicing pharmacists.

Corresponding Author: Jacqueline M. Theodorou, Department of Pharmacy Practice, Temple University School of Pharmacy, 3307 North Broad St., Philadelphia, PA 19140. Tel: 215-707-4914. Fax: 215-707-8326. E-mail: jacqueline. theodorou@temple.edu
Specifically, Doctor of Pharmacy (PharmD) graduates are expected to "actively participate and engage as a healthcare team member by demonstrating mutual respect, understanding, and values to meet patient care needs." 3 The Commission on Dental Accreditation (CODA) 2016 Standards include similar requirements for interprofessional collaboration in Standard 2-19, which states that graduates of dental education programs "must be competent in communicating and collaborating with other members of the health care team to facilitate the provision of health care." ${ }^{4}$ The Standard further states that students should receive education about and participate in clinical experiences working with other health care professional students and practitioners. ${ }^{4}$

Currently, there is no gold standard for designing or implementing IPE into health profession curricula. As a result, there are a variety of designs and implementation strategies reported in the literature. ${ }^{5-22}$ Within the pharmacy curriculum, the expectations for introductory pharmacy practice experiences (IPPEs) are that they "expose students to common contemporary U.S. practice models, including interprofessional practice involving shared patient 


\section{American Journal of Pharmaceutical Education 2018; 82 (6) Article 6298.}

care decision-making." "Thus, it is reasonable to consider that incorporation of IPE into IPPEs could satisfy objectives for both experiences. Although many pharmacy schools have reported incorporating IPE into IPPEs, little literature exists regarding IPE involving pharmacy and dental students. $^{23,24}$

Temple University School of Pharmacy (TUSP) has established a longitudinal curricular framework for IPE that is designed in a developmentally appropriate manner, specifically, through exposure to and immersion in the first- and second-professional year (P1 and P2), practice in the third-professional year (P3), and demonstration of competence in the fourth-professional year (P4). In $\mathrm{P} 3$, students are given opportunities to practice interprofessional skills and behaviors during interprofessional practice experiences and/or simulations within the IPPE curriculum.

Prior to the development of this practice experience at Temple University, there were minimal opportunities for pharmacy and dental students to collaborate as part of an interprofessional team. Thus, TUSP partnered with Temple University Kornberg School of Dentistry (TUKSoD) to create an interprofessional practice experience with the goal of meeting both IPE accreditation standards and curricular needs for P3 pharmacy students and third- and fourth-year dental students. The objective of this research article is to describe the design and evaluation of this innovative interprofessional practice experience. The curricular goals for pharmacy and dental students were similar and aligned with profession-specific accreditation standards. To evaluate these goals, student perceptions of and performance in interprofessional collaboration were measured. By implementing this interprofessional practice experience, the authors of this study hypothesized that students would express positive perceptions of and demonstrate competence in interprofessional collaboration.

\section{METHODS}

An interprofessional practice experience in TUKSoD's dental admissions clinic was designed within the framework of the P3 IPPE curriculum and clinical training assignments for dental students. It was first piloted for one P3 IPPE section of pharmacy students and dental students rotating through the clinic during Wednesday afternoons in the spring 2015 semester. After the pilot semester, the interprofessional practice experience was expanded to two afternoon sessions per week (as two separate IPPE sections) during the fall and spring semesters. Each interprofessional IPPE was divided into two 6-week experiences for pharmacy students: warfarin education conducted at Temple University Hospital (TUH) and medication histories and tobacco cessation education conducted at the dental admissions clinic. Each interprofessional IPPE section was divided into two groups of four to five students. The first group completed the first 6 weeks at TUH and the second 6 weeks at the dental admissions clinic; and the second group completed the 6 weeks in reverse order. Third- and fourth-year dental students participating in the interprofessional practice experience varied by day according to their clinical training assignments.

Curricular goals and objectives for the pharmacy and dental students were agreed upon by pharmacy and dental faculty prior to implementation, and were linked to the four core competencies of interprofessional collaboration as defined by the Interprofessional Education Collaborative (IPEC). ${ }^{25}$ Specifically, the curricular goal for pharmacy students was to prepare them to "provide entrylevel, patient-centered care in a variety of practice settings as a contributing member of an interprofessional team;" whereas the curricular goal for dental students was to prepare students to "be competent in communicating and collaborating with other members of the health care team to facilitate the provision of health care."1,4 Educational objectives were developed to align with professionspecific curricular goals.

Each day during the interprofessional practice experience at the dental admissions clinic, approximately four to five pharmacy students were paired with dental students in a 1:1 or 2:1 ratio, depending on patient workload. Prior to the dental encounter, pharmacy and dental faculty pre-briefed with each interprofessional team to verbally review the expectations of the practice experience. Each team briefly reviewed their patient's intake form, which contained self-reported past medical history, current medications, and other pertinent information, prior to beginning the dental encounter. During the encounter, pharmacy students took the lead in completing the medication history, performing medication reconciliation from the patient's pharmacy when necessary, and resolving medication discrepancies. The dental students actively observed the pharmacy students by asking questions to clarify unfamiliar components such as medication doses, therapeutic classes, and side effects, as well as contributing their own thoughts. During the encounter, dental students were responsible for completing the other medical history components, oral examinations, and demonstrating the oral cancer screening for the pharmacy student to actively observe. After completing the histories and examinations, the interprofessional team gave a shared patient presentation to the dental and pharmacy faculty and patient care plans were created. After presenting the patient, both pharmacy and dental students documented notes in the patient's chart. 


\section{American Journal of Pharmaceutical Education 2018; 82 (6) Article 6298.}

Beginning in the fall 2015 semester, a tobacco cessation education component was added to the practice experience. On non-interprofessional care days, dental students provided previously-established standard of care by screening patients for tobacco use, advising tobacco users to quit, and referring interested patients to the Pennsylvania (PA) Free Quitline. On interprofessional care days, dental students additionally referred tobacco users to the pharmacy students, who incorporated the 5-As method (Ask, Advise, Assess, Assist, and Arrange). ${ }^{26}$

To evaluate pharmacy student performance in interprofessional collaboration, a Standardized Pharmacy Student Assessment Rubric that was adapted from the existing IPPE was created (Appendix 1). ${ }^{25,27}$ Pharmacy faculty used this rubric to perform formative and summative evaluations during the practice experience. To evaluate pharmacy and dental student perceptions regarding the practice experience, the Student Perceptions of Interprofessional Clinical Education-Revised (SPICE-R) Instrument was used (Appendix 2). ${ }^{28}$ SPICE-R is a validated instrument revised from the Student Perceptions of Physician-Pharmacist Interprofessional Clinical Education (SPICE) instrument to remove profession-specific language to allow other health professions to use it. ${ }^{16,29}$ The SPICE-R instrument contains items and factors focused on interprofessional teamwork and team-based practice, roles and responsibilities for collaborative practice, and patient outcomes from collaborative practice. ${ }^{28}$ The SPICE-R tool uses a 5 -point Likert-type scale $(5=$ strongly agree; $1=$ strongly disagree). Pharmacy students completed anonymous pre- and post-SPICE-R surveys during the orientation and at the end of the 6-week interprofessional practice experience, respectively. Due to the differences in scheduling for dental students, they completed anonymous pre-SPICE-R surveys immediately before the interprofessional patient encounter and anonymous post-SPICE- $R$ surveys upon completion of the encounter. Additionally, pharmacy student perceptions regarding achievement of pre-specified educational objectives were measured at the end of the 6-week practice experience using a 5-point Likert type scale. An anonymous survey was sent to pharmacy and dental faculty at the end of the spring 2016 semester to capture feedback about the practice experience. Both paper and electronic (Qualtrics, Provo, UT) surveys were used to collect student assessment data, SPICE-R responses, and student and faculty evaluations.

Quantitative data were analyzed using descriptive and inferential statistics. Pharmacy student and faculty responses on Likert-type items assessing perceived achievement of educational objectives were analyzed by calculating means, standard deviations, and frequency data for each item. The SPICE-R surveys were analyzed by first computing descriptive statistics for each item. A change score for each item was obtained by calculating the difference between the pre- and post-rating on that item. Next, the factor scores were computed. Normality was assessed by reviewing graphical distribution (ie, histogram) and analyzing skewness and kurtosis. The data was not normally distributed; therefore, non-parametric testing was used to compare pre- and post-SPICE-R data. The Wilcoxon signed-rank test was used to compare preand post-scores on each SPICE-R item, as well as the three SPICE-R factors for the pharmacy students, dental students, and all students combined. The Mann-Whitney $\mathrm{U}$ test was used to compare scores on each SPICE-R item and the three SPICE-R factors between the pharmacy and dental students. The open-ended faculty responses were analyzed qualitatively. The study was submitted to the Institutional Review Board (IRB) at Temple University. The IRB determined that the activity was not research involving human subjects as defined by the Department of Health and Human Services (DHHS) or FDA regulations and that IRB approval was not applicable.

\section{RESULTS}

Total enrollment in the interprofessional practice experience for the fall 2015 and spring 2016 semesters was 188 students: 37 (20\%) pharmacy students and $151(80 \%)$ dental students. All 37 (100\%) pharmacy students were assessed via the Standardized Pharmacy Student Assessment Rubric (Appendix 1). Assessment scores are presented in Table 1. For the summative evaluations, all pharmacy students either met or exceeded expectations at that point in the curriculum. All pharmacy students enrolled in the interprofessional practice experience completed pre- and post-SPICE-R surveys. Of the dental students enrolled in the practice experience, 92 students completed pre- and post-SPICE-R surveys for a response rate of $61 \%$. Mean scores for the SPICE-R items are presented in Table 2 . There was a statistically significant increase in the mean scores for a majority of the SPICE-R items for pharmacy and dental students. Mean scores for the SPICE-R factors are presented in Table 3. There was a statistically significant increase in the mean scores for a majority of the SPICE-R factors for pharmacy and dental students.

Twenty-five of the pharmacy students enrolled in the interprofessional practice experience completed surveys on their perceptions regarding achievement of pre-specified educational objectives for a response rate of $68 \%$. The majority of pharmacy students responded in agreement (ie, either strongly agree or agree) that the educational objectives were met. Pharmacy and dental faculty involved in the design and implementation completed 


\section{American Journal of Pharmaceutical Education 2018; 82 (6) Article 6298.}

Table 1. Pharmacy Student Performance Scores

\begin{tabular}{|c|c|c|}
\hline $\begin{array}{l}\text { Exceeds Expectations }(\text { Personal Strength })=2 \text { points; Meets } \\
\text { Expectations }=1 \text { point; Needs Improvement }=0 \text { points; Unable } \\
\text { to Assess = no score }\end{array}$ & $\begin{array}{c}\text { Formative Evaluation } \\
\text { Average Score }\end{array}$ & $\begin{array}{c}\text { Summative Evaluation } \\
\text { Average Score }\end{array}$ \\
\hline \multicolumn{3}{|l|}{ IPE Medication Histories/Reconciliation and Tobacco Cessation } \\
\hline Actively listens and answers patients' questions. (VE1) & 1.1 & 1.5 \\
\hline Asks open-ended questions during medication histories. (VE1) & 1.1 & 1.5 \\
\hline $\begin{array}{l}\text { Assures patient that medication history is confidential and } \\
\text { information will only be shared with the team. (VE2) }\end{array}$ & 1.0 & 1.4 \\
\hline $\begin{array}{l}\text { Demonstrates sensitivity to and tolerance of a diverse patient } \\
\text { population when providing care. (VE3) }\end{array}$ & 1.0 & 1.4 \\
\hline Shows respect during interprofessional interactions. (VE4) & 1.1 & 1.5 \\
\hline $\begin{array}{l}\text { Works cooperatively with patient and dental students during } \\
\text { patient evaluations. (VE5) }\end{array}$ & 1.2 & 1.5 \\
\hline $\begin{array}{l}\text { Develops a trusting relationship with patients, families, and other } \\
\text { team members during patient care. (VE6) }\end{array}$ & 1.0 & 1.4 \\
\hline $\begin{array}{l}\text { Makes legal and ethical decisions. (Global } \\
\text { Competency 04) (VE7) }\end{array}$ & 1.1 & 1.4 \\
\hline $\begin{array}{l}\text { Acts with honesty and integrity in relationships with patients, } \\
\text { families, and other team members. (VE9) }\end{array}$ & 1.1 & 1.4 \\
\hline $\begin{array}{l}\text { Introduces oneself to patient and team members and one's role on } \\
\text { the team. (RR1) }\end{array}$ & 1.0 & 1.4 \\
\hline $\begin{array}{l}\text { Uses drug information resources and preceptors in appropriate } \\
\text { situations. (RR2) }\end{array}$ & 1.0 & 1.4 \\
\hline $\begin{array}{l}\text { Participates with assigned dental students to conduct medication } \\
\text { histories for patients during health history evaluation. (RR3) }\end{array}$ & 1.1 & 1.5 \\
\hline $\begin{array}{l}\text { Communicates their responsibility to conduct medication history } \\
\text { and presents findings to attending preceptors. (RR6) }\end{array}$ & 1.0 & 1.4 \\
\hline $\begin{array}{l}\text { Provides tobacco cessation counseling using the 5-As method. } \\
\text { (RR5 \& RR9) }\end{array}$ & 1.1 & 1.4 \\
\hline $\begin{array}{l}\text { Conducts medication history and reconciles list when } \\
\text { appropriate. (CC2) }\end{array}$ & 1.1 & 1.4 \\
\hline $\begin{array}{l}\text { Presents medication history and reconciliation to attending } \\
\text { preceptors. (CC2) }\end{array}$ & 1.0 & 1.5 \\
\hline $\begin{array}{l}\text { Based on medication history, identifies and communicates } \\
\text { potential drug-related problems with treatment plan to team } \\
\text { members. (CC3) }\end{array}$ & 1.1 & 1.5 \\
\hline $\begin{array}{l}\text { Listens actively, and encourages ideas and opinions of other team } \\
\text { members. (CC4) }\end{array}$ & 1.0 & 1.4 \\
\hline $\begin{array}{l}\text { Contacts appropriate providers (eg primary care provider or } \\
\text { community pharmacist) to conduct accurate medication } \\
\text { history and reconciliation when applicable. (TT3) }\end{array}$ & 1.0 & 1.4 \\
\hline \multicolumn{3}{|l|}{ Professionalism } \\
\hline Follows work procedures and policies of the institution. & 1.0 & 1.0 \\
\hline Thinks critically to solve complex problems. & 1.0 & 1.0 \\
\hline Dresses professionally. & 1.0 & 1.0 \\
\hline Punctual. & 1.0 & 1.0 \\
\hline
\end{tabular}

Abbreviations: $\mathrm{IPE}=$ interprofessional education; $\mathrm{VE}=$ values and ethics for interprofessional practice; $\mathrm{RR}=$ roles and responsibilities; $\mathrm{CC}=$ interprofessional communication; $\mathrm{TT}=$ teams and teamwork

a post-evaluation at the end of the spring 2016 semester to provide feedback about the practice experience. All faculty completed the evaluation for a response rate of $100 \%$. All pharmacy faculty $(2 / 2 ; 100 \%)$ responded in agreement (ie, either strongly agree or agree) that the pharmacy student educational objectives were met. The majority of dental faculty (5-6/6; 83\%-100\%) responded in agreement (ie, either strongly agree or 


\section{American Journal of Pharmaceutical Education 2018; 82 (6) Article 6298.}

Table 2. Student SPICE-R Item Scores

\begin{tabular}{|c|c|c|c|c|c|c|c|c|c|c|}
\hline \multirow[b]{2}{*}{ No. } & \multirow[b]{2}{*}{ SPICE-R Items } & \multicolumn{3}{|c|}{$\begin{array}{c}\text { Dental Students } \\
\text { Pre-Post Averages }\end{array}$} & \multicolumn{3}{|c|}{$\begin{array}{l}\text { Pharmacy Students } \\
\text { Pre-Post Averages }\end{array}$} & \multicolumn{3}{|c|}{$\begin{array}{c}\text { All Students } \\
\text { Pre-Post Averages }\end{array}$} \\
\hline & & $\begin{array}{c}\text { Pre } \\
\mathrm{N}=\mathbf{8 8}\end{array}$ & $\begin{array}{c}\text { Post } \\
\mathrm{N}=\mathbf{8 0}\end{array}$ & $\begin{array}{c}p \\
\text { value }\end{array}$ & $\begin{array}{c}\text { Pre } \\
\mathrm{N}=36\end{array}$ & $\begin{array}{c}\text { Post } \\
\mathbf{N}=\mathbf{3 7}\end{array}$ & $\begin{array}{c}p \\
\text { value }\end{array}$ & $\begin{array}{c}\text { Pre } \\
\mathrm{N}=124\end{array}$ & $\begin{array}{c}\text { Post } \\
\mathrm{N}=117\end{array}$ & $\begin{array}{c}p \\
\text { value }\end{array}$ \\
\hline 1 & $\begin{array}{l}\text { Working with students from another health } \\
\text { profession enhances my education. }\end{array}$ & 4.32 & 4.54 & $<.001$ & 4.19 & 4.51 & .006 & 4.28 & 4.53 & $<.001$ \\
\hline 2 & $\begin{array}{l}\text { My role within an interprofessional health care team } \\
\text { is clearly defined. }\end{array}$ & 4.16 & 4.43 & $<.001$ & 3.94 & 4.27 & .019 & 4.10 & 4.38 & $<.001$ \\
\hline 3 & $\begin{array}{l}\text { Health outcomes are improved when patients are } \\
\text { treated by a team that consists of individuals from } \\
\text { two or more health professions. }\end{array}$ & 4.41 & 4.59 & .001 & 4.58 & 4.65 & .536 & 4.46 & 4.61 & .008 \\
\hline 4 & $\begin{array}{l}\text { Patient satisfaction is improved when patients are } \\
\text { treated by a team that consists of individuals from } \\
\text { two or more health professions. }\end{array}$ & 4.07 & 4.41 & $<.001$ & 4.44 & 4.57 & .412 & 4.18 & 4.46 & $<.001$ \\
\hline 5 & $\begin{array}{l}\text { Participating in educational experiences with students } \\
\text { from another health profession enhances my future } \\
\text { ability to work on an interprofessional team. }\end{array}$ & 4.41 & 4.60 & $<.001$ & 4.25 & 4.57 & .054 & 4.36 & 4.59 & $<.001$ \\
\hline 6 & $\begin{array}{l}\text { All health professional students should be educated } \\
\text { to establish collaborative relationships with members } \\
\text { of other health professions. }\end{array}$ & 4.41 & 4.61 & $<.001$ & 4.22 & 4.54 & .046 & 4.35 & 4.59 & $<.001$ \\
\hline 7 & $\begin{array}{l}\text { I understand the roles of other health professionals } \\
\text { within an interprofessional team. }\end{array}$ & 4.13 & 4.54 & $<.001$ & 3.83 & 4.41 & .001 & 4.04 & 4.50 & $<.001$ \\
\hline 8 & $\begin{array}{l}\text { Clinical rotations are the ideal place within their } \\
\text { respective curricula for health professional students } \\
\text { to interact. }\end{array}$ & 4.23 & 4.50 & $<.001$ & 4.06 & 4.65 & $<.001$ & 4.18 & 4.55 & $<.001$ \\
\hline 9 & $\begin{array}{l}\text { Health professionals should collaborate on } \\
\text { interprofessional teams. }\end{array}$ & 4.35 & 4.61 & $<.001$ & 4.33 & 4.62 & .088 & 4.35 & 4.62 & $<.001$ \\
\hline 10 & $\begin{array}{l}\text { During their education, health professional students } \\
\text { should be involved in teamwork with students from } \\
\text { other health professions in order to understand } \\
\text { their perspective. }\end{array}$ & 4.38 & 4.60 & $<.001$ & 4.33 & 4.68 & .032 & 4.36 & 4.62 & $<.001$ \\
\hline
\end{tabular}

Abbreviations: SPICE-R = Student Perceptions of Interprofessional Clinical Education-Revised

${ }^{a}$ Wilcoxon Ranked Test to examine within group changes pre-post

agree) that the dental student educational objectives were met.

Overall, faculty perceptions and open-ended responses regarding the practice experience were positive. Positive feedback from the open-ended responses included perceptions that the interprofessional practice experience increased teamwork, as well as knowledge about roles and pharmacotherapy. For example, one faculty member responded that pharmacy students "learned how to work in an interprofessional education environment with the dental students in the dental clinic setting. . . about their role as a pharmacy student and how vital it is to patient care, as well as the dental student's role in taking medical histories, performing oral cancer screenings, and assessing the dental needs of the patients." Negative feedback included variability in student engagement (eg, "[Pharmacy students] did not ask questions to increase knowledge about profession of dentistry"), variability in knowledge gained among students (eg, "I am not sure how much they [pharmacy students] actually learned about the dental students 


\section{American Journal of Pharmaceutical Education 2018; 82 (6) Article 6298.}

Table 3. Pre-Post SPICE-R Factor Scores

\begin{tabular}{|c|c|c|c|c|c|c|c|c|c|c|}
\hline \multirow[b]{2}{*}{ Factors } & \multicolumn{3}{|c|}{ Dental Students } & \multicolumn{3}{|c|}{ Pharmacy Students } & \multirow[b]{2}{*}{$\begin{array}{l}\text { Pre-Post } \\
\text { Compare }^{\text {a }}\end{array}$} & \multicolumn{3}{|c|}{ All Students } \\
\hline & $\begin{array}{c}\text { Pre } \\
\mathrm{N}=\mathbf{8 8}\end{array}$ & $\begin{array}{l}\text { Post } \\
\mathbf{N}=\mathbf{8 0}\end{array}$ & $\begin{array}{l}\text { Change } \\
\text { Score }^{a, b}\end{array}$ & $\begin{array}{c}\text { Pre } \\
\mathrm{N}=36\end{array}$ & $\begin{array}{l}\text { Post } \\
\mathbf{N}=\mathbf{3 7}\end{array}$ & $\begin{array}{l}\text { Change } \\
\text { Score }\end{array}$ & & $\begin{array}{c}\text { Pre } \\
N=124\end{array}$ & $\begin{array}{c}\text { Post } \\
\mathrm{N}=117\end{array}$ & $\begin{array}{l}\text { Change } \\
\text { Score }^{a, b}\end{array}$ \\
\hline $\begin{array}{l}\text { Inter-professional teamwork and } \\
\text { team-based practice }\end{array}$ & 4.35 & 4.58 & .26 & 4.23 & 4.6 & .35 & $p=.004$ & 4.31 & 4.58 & .29 \\
\hline $\begin{array}{l}\text { Roles/responsibilities for } \\
\text { collaborative practice }\end{array}$ & 4.14 & 4.48 & .33 & 3.89 & 4.34 & .49 & $p=.001$ & 4.07 & 4.44 & .38 \\
\hline $\begin{array}{l}\text { Patient outcomes from } \\
\text { collaborative practice }\end{array}$ & 4.24 & 4.5 & .28 & 4.51 & 4.6 & .11 & $p=.424$ & 4.32 & 4.53 & .23 \\
\hline
\end{tabular}

Abbreviations: SPICE-R=Student Perceptions of Interprofessional Clinical Education-Revised

${ }^{a}$ Wilcoxon Signed Ranked Test to examine differences between pre- and post-scores

${ }^{\mathrm{b}} p<.001$

and about the dental students' roles and responsibilities on the team"), and workflow issues (eg, "Potentially longer appointment times for patients. Prolonged chair time which could disrupt the "flow' of the clinic"). All pharmacy and dental faculty $(n=8)$ reported being satisfied with the experience (3 [38\%] extremely satisfied; 3 [38\%] very satisfied; 2 [25\%] satisfied).

\section{DISCUSSION}

Student perceptions of and performance in interprofessional collaboration were measured to evaluate curricular goals of preparing pharmacy and dental students to provide patient care as a member of an interprofessional team. The authors hypothesized that by implementing this interprofessional practice experience, students would express positive perceptions of and demonstrate competence in interprofessional collaboration.

This interprofessional practice experience satisfied both pharmacy and dental accreditation standards for interprofessional education, which was a previous gap in both curricula. The unique design contains key elements from the ACPE Standards, notably, incorporation into experiential curricula to provide opportunities to practice and reinforce interprofessional collaboration. ${ }^{1}$ The dental accreditation standards are less prescriptive and include intent statements for IPE, which were also met with this practice experience.

Overall, there was a statistically significant increase in mean scores measuring student perceptions of IPE, in regards to teamwork, roles/responsibilities, and patient outcomes, which is similar to previously published studies. ${ }^{16,30,31}$ The evaluation from this study is unique from other literature because multiple types of assessment data in addition to student perceptions, specifically, student and faculty evaluations and pharmacy student performance, were measured. The fact that all 37 (100\%) pharmacy students demonstrated competence in interprofessional collaboration suggests that a standardized assessment rubric that is specific to the educational setting and linked to behavior-based objectives of the IPEC core competencies can be used to ensure achievement of IPE curricular goals. Overall, pharmacy students and faculty agreed that the pre-specified learning objectives were met, which suggests that evaluation of student perceptions in conjunction with performance assessment can be used as a strategy to demonstrate learner outcomes within IPE.

When evaluating changes in student perceptions by profession, most of the mean scores increased significantly from baseline; however, there were differences among dental and pharmacy students which is commonly reported in the literature. ${ }^{16,31-33}$ These differences may have been affected by several factors. First, most students reported positive perceptions at baseline, which makes it difficult to observe significant increases. Positive perceptions at baseline is not uncommon and has been previously reported in the literature as rationale for non-significant changes. ${ }^{17,21}$ Second, the relatively small sample size of pharmacy students $(\mathrm{N}=37)$ requires larger differences to reach statistical significance compared to the larger sample size of dental students $(\mathrm{N}=92)$. Third, some of the mean scores for pharmacy students decreased after the experience; thus, with the small sample size, this could have led to non-significance. Another important factor is the difference in timing of pre- and post-surveys between pharmacy and dental students. Pharmacy students had either 7 or 13 weeks between the pre- and post-surveys depending on if they were in the first or second group. Whereas the dental students had roughly one to two hours between the pre- and postsurveys. This difference in timing between the pre- and post-surveys could have led to differences in changes 


\section{American Journal of Pharmaceutical Education 2018; 82 (6) Article 6298.}

between pharmacy and dental student perceptions. Finally, anecdotally, dental students did not always collaborate on the medication history component of the patient encounter. This could be related to the fact that the interprofessional practice experience was scheduled on only two afternoons per week. During the rest of the week, dental students were responsible for conducting the entire patient encounter on their own (including taking the medication history). Thus, it is possible some dental students may have forgotten to share responsibilities with the pharmacy students. These factors likely had an impact on pharmacy student perceptions.

Although most faculty perceptions and open-ended responses regarding the practice experience were positive, there was some negative feedback, specifically, variability in both engagement and knowledge gained among students, as well as workflow issues. This feedback is not surprising, as it was collected at the end of the spring 2016 semester, which provided faculty a significant amount of time to formulate both positive and negative opinions about the practice experience, as well as identify ways to improve upon it. Additionally, although pharmacy and dental faculty provided support and oversight for the interprofessional teams, it was not possible to observe every single interaction between the pharmacy and dental students to ensure optimal interprofessional collaboration and communication, which may account for the reported perceptions of variability in student engagement and knowledge gained. Lastly, workflow issues are expected in any new practice experience, especially when adding an interprofessional component to the workflow of an existing dental clinic.

There are notable strengths of the design and evaluation of this interprofessional practice experience. First, designing IPE within a direct patient care setting provides students an opportunity to apply knowledge and practice skills learned in profession-specific didactic curricula, while also learning how to practice and demonstrate skills and behaviors of interprofessional collaboration. Second, for the pharmacy students, the longitudinal design further afforded them the opportunity to practice and reinforce these skills and behaviors in order to demonstrate competence. Third, faculty incorporated best practice tips for interprofessional co-precepting that involved role modeling interprofessional collaboration and providing targeted feedback to individual students and student teams, which has demonstrated facilitation of collaborative learning in previous studies. $^{34}$

There were a few notable obstacles during the implementation and evaluation of this interprofessional practice experience. Specifically, the interprofessional practice experience was embedded into an existing dental clinic, which led to anticipated challenges when changing a previously established workflow. Additionally, due to differences in the extent of orientation, dental students were not always adequately prepared to collaborate with the pharmacy students. Both obstacles were resolved with preceptors and students being flexible and adapting to the workflow. Additionally, pharmacy faculty are now incorporated into the dental student orientation to review the practice experience expectations and workflow, and reinforce the importance of collaboration. An anticipated barrier with gaining dental faculty buy-in was managed by involving dental faculty who practice within the admissions clinic from the start of the design and implementation phases. Involving these key players in the decision-making process ensured their investment in the practice experience. Scheduling and logistical challenges from previous experience in designing an interprofessional practice experience were expected. ${ }^{15,35}$ By combining existing curricular requirements (IPPEs for pharmacy students and clinical training assignments for dental students) rather than incorporating an additional requirement into overcrowded curricula, these challenges were overcome. Another obstacle for the sustainability of this practice experience was faculty workload. This practice experience required approximately 40 contact hours each semester per pharmacy faculty member, which is roughly a one-third increase in contact hours compared to the previously established pharmacy faculty workload requirements. At TUSP, pharmacy faculty typically share the IPPE precepting by alternating weeks, which was not possible with the design of this interprofessional practice experience. To address the increased workload requirements, pharmacy and dental faculty are working to redesign the practice experience to allow for shared precepting among pharmacy faculty. To stay current, pharmacy and dental faculty meet on a regular basis to revise and incorporate student and faculty feedback to increase the quality of the interprofessional practice experience.

There are limitations to the design and evaluation of this interprofessional practice experience. First, dental students did not receive individualized formal performance assessments for interprofessional collaboration because formal assessments were not standard practice within the dental admissions clinic. Second, due to the workflow of the clinic and faculty workload, it was not possible to incorporate formal team performance assessments. Evaluating each team's ability to function and provide collaborative care is an important but challenging task and future studies in this area should be performed. Third, the number of faculty included in the development, implementation, and evaluation of this experience is 


\section{American Journal of Pharmaceutical Education 2018; 82 (6) Article 6298.}

relatively low compared to the number of students enrolled, which could limit generalizability of their feedback. Finally, inherent to all faculty evaluations, there could be potential variability in pharmacy faculty rating of pharmacy student performance assessments; however, using a standardized rubric reduces this variability.

\section{CONCLUSION}

This interprofessional practice experience was designed to satisfy IPE accreditation standards, as well as to better prepare students to build more effective collaborative health care teams. Pharmacy student performance met or exceeded expectations at the summative evaluation. Overall, mean scores measuring student perceptions of interprofessional collaboration increased after the practice experience. Most students and faculty agreed that the learning objectives of this practice experience were achieved. These findings demonstrate the impact of an innovative pharmacy-dentistry collaboration, and underpin the importance of evaluating performance and perceptions when implementing an interprofessional practice experience at other institutions. Although this report focuses on a pharmacy-dental IPE collaboration, the design and evaluation methods can be implemented at other health profession schools in a variety of practice settings.

\section{ACKNOWLEDGMENTS}

The authors wish to acknowledge Temple University School of Pharmacy and Temple University Kornberg School of Dentistry for supporting this endeavor and allowing this practice experience to be incorporated into existing workflow. The authors would also like to acknowledge Temple University School of Pharmacy's Experiential Office for support with coordinating the scheduling of the practice experience.

\section{REFERENCES}

1. Accreditation Council for Pharmacy Education. Accreditation standards and key elements for the professional program in pharmacy leading to the doctor of pharmacy degree. Standards 2016. https:// www.acpe-accredit.org/pdf/Standards2016FINAL.pdf. Accessed December 12, 2016.

2. Accreditation Council for Pharmacy Education. Guidance for the accreditation standards and key elements for the professional program in pharmacy leading to the doctor of pharmacy degree. https://www.acpe-accredit.org/pdf/ GuidanceforStandards2016FINAL.pdf. Accessed December 12, 2016.

3. Medina MS, Plaza CM, Stowe CD, et al. Center for the Advancement of Pharmacy Education 2013 educational outcomes. Am J Pharm Educ. 2013;77(8):Article 162.

4. Commission on Dental Accreditation. Accreditation standards for dental education programs. Chicago, IL: Commission on Dental Accreditation; 2016.
5. Cameron A, Ignjatovic M, Langlois $\mathrm{S}$, et al. An interprofessional education session for first-year health science students. Am J Pharm Educ. 2009;73(4):Article 62.

6. MacDonnell CP, Rege SV, Misto K, Dollase R, George P. An introductory interprofessional exercise for healthcare students. $\mathrm{Am} \mathrm{J}$ Pharm Educ. 2012;76(8):Article 154.

7. King J, Beanlands S, Fiset V, et al. Using interprofessional simulation to improve collaborative competences for nursing, physiotherapy, and respiratory therapy students. $J$ Interprof Care. 2016;30(5):599-605.

8. MacDonnell C, George P, Nimmagadda J, Brown S, Gremel K. A team-based practicum bringing together students across educational institutions and health professions. Am J Pharm Educ. 2016;80(3): Article 49.

9. Shoemaker MJ, de Voest M, Booth A, Meny L, Victor J. A virtual patient educational activity to improve interprofessional competencies: a randomized trial. J Interprof Care. 2015;29(4):395-397.

10. Shrader S, McRae L, King WM, Kern D. A simulated interprofessional rounding experience in a clinical assessment course. Am J Pharm Educ. 2011;75(4):Article 61.

11. Erickson JM, Brashers V, Owen J, Marks JR, Thomas SM.

Effectiveness of an interprofessional workshop on pain

management for medical and nursing students. J Interprof Care. 2016;30(4):466-474.

12. Farlow JL, Goodwin C, Sevilla J. Interprofessional education through service-learning: lessons from a student-led free clinic.

$J$ Interprof Care. 2015;29(3):263-264.

13. Sevin AM, Hale KM, Brown NV, McAuley JW. Assessing interprofessional education collaborative competencies in servicelearning course. Am J Pharm Educ. 2016;80(2):Article 32.

14. Wang J, Hu X, Liu J, Li L. Pharmacy students' attitudes towards physician-pharmacist collaboration: Intervention effect of integrating cooperative learning into an interprofessional team-based community service. J Interprof Care. 2016;30(5):591-598.

15. Rotz ME, Dueñas GG, Zanoni A, Grover AB. Designing and evaluating an interprofessional experiential course series involving medical and pharmacy students. Am J Pharm Educ. 2016;80(5): Article 85.

16. Zorek JA, MacLaughlin EJ, Fike DS, MacLaughlin AA, Samiuddin M, Young RB. Measuring changes in perception using the student perceptions of physician-pharmacist interprofessional clinical education (SPICE) instrument. BMC Med Educ. 2014;14:101.

17. Seif G, Coker-Bolt P, Kraft S, Gonsalves W, Simpson K, Johnson E. The development of clinical reasoning and interprofessional behaviors: service-learning at a student-run free clinic. J Interprof Care. 2014;28(6):559-564.

18. Van Winkle LJ, Bjork BC, Chandar N, et al. Interprofessional workshop to improve mutual understanding between pharmacy and medical students. Am J Pharm Educ. 2012;76(8):Article 150.

19. Conti G, Bowers C, O'Connell MB, et al. Examining the effects of an experiential interprofessional education activity with older adults. J Interprof Care. 2016;30(2):184-190.

20. Nuffer W, Gilliam E, McDermott M, Turner CJ. Sustainability of a practice-based interprofessional introductory pharmacy practice experience course. Am J Pharm Educ. 2015;79(5):Article 62. 21. Shrader S, Griggs C. Multiple interprofessional education activities delivered longitudinally within a required clinical assessment course. Am J Pharm Educ. 2014;78(1):Article 14. 22. Arenson C, Umland E, Collins L, et al. The health mentors program: three years experience with longitudinal, patient-centered interprofessional education. J Interprof Care. 2015;29(2):138-143. 


\section{American Journal of Pharmaceutical Education 2018; 82 (6) Article 6298.}

23. Jones KM, Blumenthal DK, Burke JM, et al. Interprofessional education in introductory pharmacy practice experiences at US colleges and schools of pharmacy. Am J Pharm Educ. 2012;76(5): Article 80.

24. Palatta A, Cook BJ, Anderson EL, Valachovic RW. 20 years beyond the crossroads: the path to interprofessional education at U.S. dental schools. J Dent Educ. 2015;79(8):982-996.

25. Interprofessional Education Collaborative Expert Panel. Core competencies for interprofessional collaborative practice: report of an expert panel. Washington, DC: Interprofessional Education Collaborative; 2011. http://www.pharmacy.arizona.edu/sites/default/ files/pdfs/IPECoreCompetenciesMay2011.pdf.

26. Quinn VP, Hollis JF, Smith KS, et al. Effectiveness of the 5-As tobacco cessation treatments in nine HMOs. J Gen Intern Med. 2009;24(2):149-154.

27. Interprofessional Education Collaborative. Core competencies for interprofessional collaborative practice: 2016 update.

Washington, DC: Interprofessional Education Collaborative; 2016.

28. Dominguez DG, Fike DS, MacLaughlin EJ, Zorek JA. A comparison of the validity of two instruments assessing health professional student perceptions of interprofessional education and practice. J Interprof Care. 2015;29(2):144-149.

29. Fike DS, Zorek JA, MacLaughlin AA, Samiuddin M, Young RB, MacLaughlin EJ. Development and validation of the student perceptions of physician-pharmacist interprofessional clinical education (SPICE) instrument. Am J Pharm Educ. 2013;77(9):Article 190.

30. Curran VR, Sharpe D, Flynn K, Button P. A longitudinal study of the effect of an interprofessional education curriculum on student satisfaction and attitudes towards interprofessional teamwork and education. J Interprof Care. 2010;24(1):41-52.

31. Horsburgh M, Lamdin R, Williamson E. Multiprofessional learning: the attitudes of medical, nursing and pharmacy students to shared learning. Med Educ. 2001;35(9):876-883.

32. Gunaldo TP, Andrieu SC, Garbee D, et al. Student perceptions about interprofessional education after an elective course. $J$ Interprof Care. 2015;29(4):370-371.

33. Rotz M, Grover AB, Burden A, Pontiggia L, Duenas GG. A cross-sectional study evaluating the impact of one year versus two years of exposure to interprofessional education on student perceptions of physician-pharmacist interprofessional clinical education (SPICE). Innov Pharm. 2016;7(3).

34. National Center for Interprofessional Practice and Education. Preceptors in the Nexus toolkit interprofessional precepting: best practices. https://nexusipe.org/engaging/learning-system/preceptorsnexus-toolkit. Accessed November 28, 2016.

35. Rotz ME, Dueñas GG. “Collaborative-ready” students: exploring factors that influence collaboration during a longitudinal interprofessional education practice experience. J Interprof Care. 2016;30(2):238-241. 


\section{American Journal of Pharmaceutical Education 2018; 82 (6) Article 6298.}

Appendix 1. Standardized Assessment Rubric

Student Name:

Student Evaluation 2015-2016 Interprofessional IPPE

Instructions: Please evaluate this third-year pharmacy student on their ability to complete each of the following objectives.

$\mathrm{EX}=$ Exceeds Expectations (personal strength) $=2$ points; $\mathrm{ME}=$ Meets Expectations $=1$ point; $\mathrm{NI}=\mathrm{Needs}$ Improvement $=0$ points; $\mathrm{UA}=$ Unable to Assess $=$ no score

Formative Evaluation - Summative Evaluation Please comment on Please comment on areas that require areas that require improvement remediation $\dagger$

Objectives

EX ME NI Comments EX ME NI Comments

Actively listens and answers patients' questions. (VE1)

Asks open-ended questions. (VE1)

Assures patient that session is confidential and information will only be shared with the team. (VE2)

Demonstrates sensitivity to and tolerance of a diverse patient population when providing care. (VE3)

Shows respect during interprofessional interactions. (VE4)

Works cooperatively with patient and dental students during patient evaluations. (VE5)

Develops a trusting relationship with patients, families, and other team members during patient care. (VE6)

Makes legal and ethical decisions. (Global Competency 04) (VE7)

Acts with honesty and integrity in relationships with patients, families, and other team members. (VE9)

Introduces oneself to patient and team members, and one's role on the team. (RR1)

Uses drug information resources \& preceptors appropriately. (RR2)

Participates with assigned dental students to conduct medication histories and tobacco cessation counseling. (RR3)

Communicates their responsibility to conduct medication history and/or tobacco cessation counseling and presents findings to attending preceptors.* (RR6)

Provides tobacco cessation counseling using the 5-As method. (RR5 \& RR9)

Conducts medication history and reconciles list when appropriate. (CC2)

Presents medication history/rec to attending preceptors.* (CC2)

Based on medication history, identifies and communicates potential drugrelated problems with treatment plan to team members. (CC3)

For tobacco users, recommends appropriate pharmacotherapy that is patient specific to treat nicotine dependence. (CC3)

Listens actively, encourages ideas and opinions of other team members. (CC4)

Contacts appropriate providers (eg, primary care provider or community pharmacist) to conduct accurate medication history and reconciliation when applicable. (TT3)

*[If dental student needs to be signed off for a competency, pharmacy student will not present findings to attending in this situation.] $\mathrm{VE}=$ values and ethics for interprofessional practice; $\mathrm{RR}=$ roles and responsibilities; $\mathrm{CC}=$ interprofessional communication; $\mathrm{TT}=$ teams and teamwork 
American Journal of Pharmaceutical Education 2018; 82 (6) Article 6298.

\begin{tabular}{|c|c|c|c|c|c|c|}
\hline \multirow[b]{2}{*}{ Professionalism Objectives } & \multicolumn{3}{|c|}{ Formative Evaluation } & \multicolumn{3}{|c|}{ Summative Evaluation } \\
\hline & ME & NI & Comments & ME & NI & Comments \\
\hline $\begin{array}{l}\text { Follows work procedures and policies of the institution. } \\
\text { Thinks critically to solve complex problems. } \\
\text { Dresses professionally. } \\
\text { Punctual. }\end{array}$ & & & & & & \\
\hline
\end{tabular}

Formative Evaluation

Preceptor Signature:

Student Signature:
Date:

Date:
Summative Evaluation

Preceptor Signature:

Student Signature:
Date: Date:

\section{Appendix 2. Student Perceptions of Interprofessional Clinical Education-Revised (SPICE-R) Instrument ${ }^{33}$}

Dear Health Professional Student:

In this survey, you are being asked about your attitudes toward interprofessional health care teams and the team approach to patient care. By interprofessional health care team, we mean two or more health professionals (eg, nurse, pharmacist, dentist, physician, etc.) who work together to plan, coordinate, and/or deliver patient care. Please be candid as you indicate the extent of your agreement with each of the following statements related to interprofessional teams and the team approach to care.

\section{Statement}

Working with students from another health profession enhances my education.

My role within an interprofessional healthcare team is clearly defined.

Health outcomes are improved when patients are treated by a team that consists of individuals from two or more health professions.

Patient satisfaction is improved when patients are treated by a team that consists of individuals from two or more health professions.

Participating in educational experiences with students from another health profession enhances my future ability to work on an interprofessional team.

All health professional students should be educated to establish collaborative relationships with members of other health professions.

I understand the roles of other health professionals within an interprofessional team.

Clinical rotations are the ideal place within their respective curricula for health professional students to interact.

Health professionals should collaborate on interprofessional teams.

During their education, health professional students should be involved in teamwork with students from other health professions in order to understand their respective roles.

$1=$ strongly disagree, $2=$ disagree, $3=$ neutral, $4=$ agree, $5=$ strongly agree 